\title{
Genetic mouse models of essential tremor: are they essential?
}

\author{
Joseph Jankovic and Jeffrey L. Noebels
}

Department of Neurology, Baylor College of Medicine, Houston, Texas, USA.

\begin{abstract}
The causative genes for essential tremor (ET), one of the most common genetic neurological disorders, have eluded scientists despite intensive search. Two gene loci linked to ET, one on chromosome 3q13 and another on chromosome $2 \mathrm{p} 24.1$, have been identified, and a missense mutation in the HS1-BP3 gene on the $2 \mathrm{p}$ has been suggested as the cause of the disorder in about $10 \%$ of American ET patients. Therefore, the genetic basis for the vast majority of familial ET is still unknown. In this issue of the JCI, the gene coding for the $\gamma$-aminobutyric $\operatorname{acid}_{A}\left(G_{A B A}\right)$ receptor $\alpha 1$ subunit is suggested as a potential candidate gene for ET, as mice lacking the gene express a phenotype that overlaps with some clinical characteristics of the human condition (see the related article beginning on page 774 ).
\end{abstract}

Essential tremor (ET), manifested by action tremor, present usually in the hands when arms are outstretched in front of the body but also involving mainly the head, vocal cords, and other parts of the body, is one of the most common neurological disorders. The prevalence of ET has been reported to range from $4 \%$ in a population aged 40 years or younger (1) to $14 \%$ in people 65 years or older (2). While it is generally recognized that ET is inherited in an autosomal-dominant pattern with high penetrance, no human gene mutations causing ET have yet been identified. Two ET loci, one on chromosome $3 q 13$ (ETM1) (3) and another on chromosome 2p24.1 (ETM2) (4), have been isolated in families from geographically distinct areas. Recently, physical mapping of the ETM2 region and systematic searching for gene mutations associated with the classic ET phenotype revealed a variation in the human homolog of the mouse HS1-binding protein 3 (HS1-BP3) gene $(H s 1 b p 3)$ in 2 unrelated ET families (5). Since the HS1-BP3 protein is highly expressed in the cerebellum and regulates the $\mathrm{Ca}^{2+} /$ calmodulin-dependent protein kinase activation of tyrosine and tryptophan hydroxylase, it represents a viable candidate gene for the disorder. While this finding promises to provide insight into the patho-

Nonstandard abbreviations used: ET, essential tremor; GABA, $\gamma$-aminobutyric acid; $\mathrm{GABA}_{\mathrm{A}}$ receptor $\alpha 1^{-/-}, \mathrm{GABA}_{\mathrm{A}}$ receptor $\alpha 1$ subunit knockout; HS1-BP3, HS1-binding protein 3; $\mathrm{Hz}$, hertz.

Conflict of interest: The authors have declared that no conflict of interest exists.

Citation for this article: J. Clin. Invest. 115:584-586 (2005). doi:10.1172/JCI200524544. genesis of some types of ET, both the ETM1 and ETM2 loci have been excluded in other families, suggesting genetic heterogeneity. Not only does ET link to multiple gene loci, but the clinical expression of the condition is highly variable (6), and ET has also been associated with a variety of comorbidities, including dystonia, parkinsonism, malignant hyperthermia, migraines, and deafness (7). In addition, phenotypes resembling ET may appear in a variety of other disorders, such as Parkinson disease and a fragile $\mathrm{X}$ premutation (8). There is increasing reason, therefore, to believe that the clinical entity known as ET, in both its pure and forme fruste forms, arises from diverse etiologies.

Anatomical and pharmacological pathways mediating ET may also be heterogeneous. Most physiological and functional imaging studies point to the involvement of cerebellar outflow circuitry in the pathophysiology of ET (9). The thalamus may also play a role in ET as high-frequency stimulation of the ventral intermediate nucleus of the thalamus produces a marked decrease in the amplitude of contralateral tremor (10). While the proposal that the neocortex is involved in ET is controversial (11), a familial postural tremor phenotypically similar to ET can be a rare manifestation of cortical reflex myoclonus (12). This "cortical tremor," which may or may not be accompanied by seizures, usually starts when the patient is between 19 and 30 years of age as tremulous finger movements and is often associated with a family history suggestive of ET. It is characterized by

\section{Pathophysiology of ET}

8- to 15-hertz (Hz) synchronous, electromyographic bursts, each lasting 10-50 ms. The condition shares neurophysiologic features with myoclonus, including giant somatosensory evoked responses, and patients respond well to anticonvulsants such as clonazepam, primidone, and valproate, but the symptoms do not improve following treatment with $\beta$ blockers, the treatment of choice for most patients with ET.

\section{Animal models of ET}

Animal models are important because they provide insights into the pathophysiology of human disease and may be useful in the development of novel drugs. At least 3 approaches have been used to produce tremor in animals: (a) administration of tremorgenic drugs such as harmaline; (b) lesioning of different subcortical structures; and (c) use of various inbred strains (13). However, only the single mutant gene models pinpoint potentially heritable causes of the disorder. Many of the mutant mouse tremor models described so far result in cerebellar degeneration and dysmyelinating phenotypes accompanied by a spectrum of ataxia, dystonia, weakness, and lethality. Given the shortage of human postmortem case material available for comparison, one inevitable difficulty in interpreting the relevance of these mouse models lies in deciding whether the tremor in each is indeed "essential."

\section{GABA receptor and ET}

In this issue of the JCI, Kralic et al. (14) describe a novel genetic model of ET in $\gamma$-aminobutyric acid $\left(\mathrm{GABA}_{\mathrm{A}}\right)$ receptor $\alpha 1$ subunit knockout $\left(\mathrm{GABA}_{\mathrm{A}}\right.$ receptor $\left.\alpha 1^{-/-}\right)$ mice. $\mathrm{GABA}_{\mathrm{A}}$ receptors are a heterogeneous family of ligand-gated chloride channels, each composed of 5 protein subunits $(2 \alpha$, $2 \beta$, and $1 \gamma$ ) encoded by 18 different genes. These channel subunits are differentially expressed in different regions, conferring a spectrum of pharmacological properties to synaptic inhibitory signaling throughout the central nervous system. Mice deficient in the $\alpha 1$ subunit display an action tremor, and Kralic et al. (14) propose that the mutant is a 


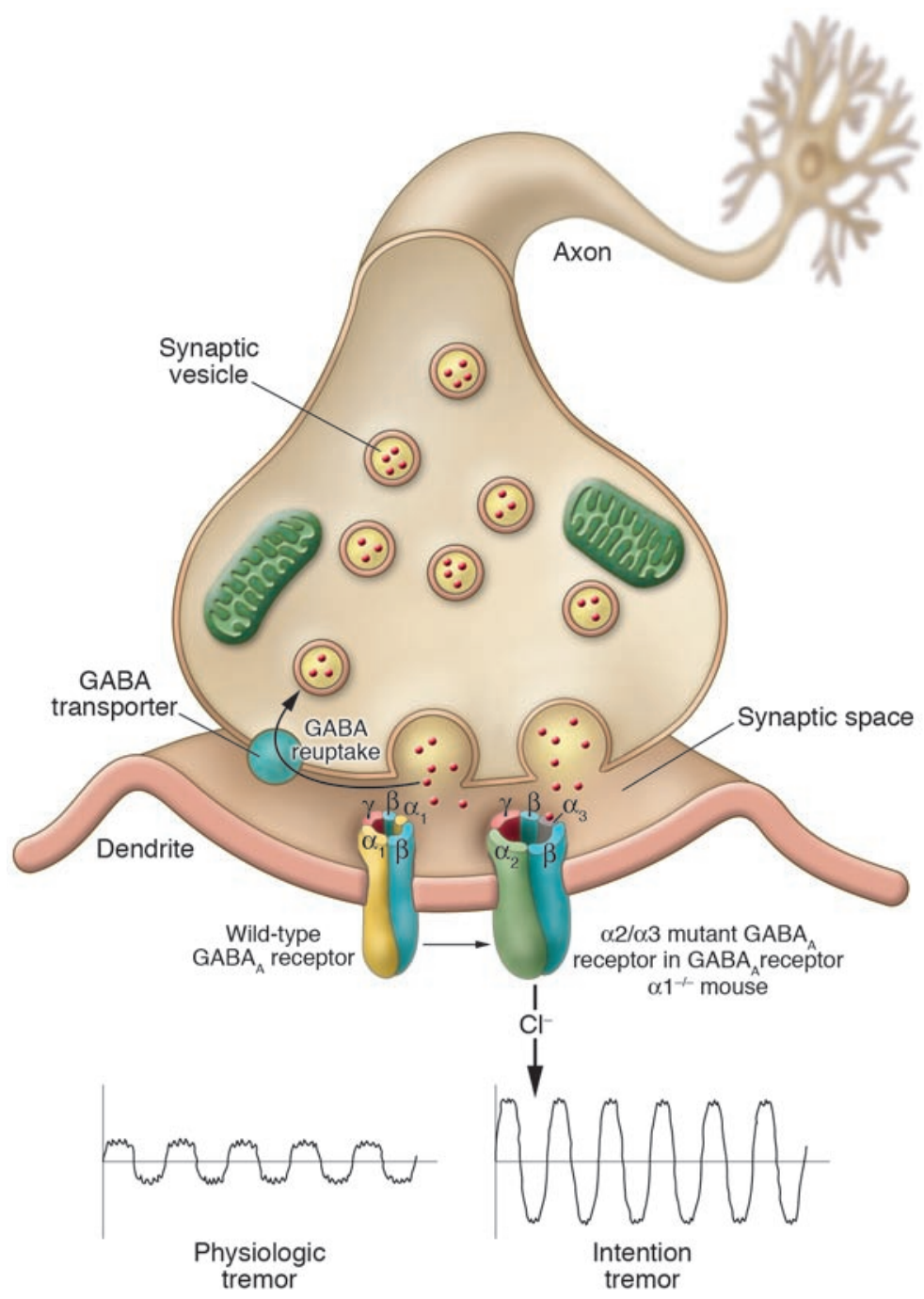

Figure 1

Molecular architecture of a GABAergic synapse showing alternative subunit switching in the $\mathrm{GABA}_{\mathrm{A}}$ receptor $\alpha 1^{-/-}$mouse.

promising model of ET because the tremor is prominent in the limbs, is pronounced upon tail suspension yet absent when the mouse is relaxed, and improves with administration of primidone, propranolol, and ethanol - the 3 agents most consistently effective in the treatment of ET.

While these features closely resemble the symptoms described for common forms of the human disorder, several dissimilarities between the described phenotype in mice and typical human ET are also worth noting. First, the onset of the movement disorder in this mouse appears earlier in its development than the typical age of onset in human ET, although ET certainly can begin during childhood (15). Moreover, the reported appearance in mice of a pathologic tremor at a frequency of $19 \mathrm{~Hz}$ is substantially higher than the 4- to 8-Hz tremor frequency typious or gait-induced axial tremor of $10-14 \mathrm{~Hz}$ measured on the cage floor is typically seen in various drug-induced and single-gene mouse models of ET, the higher frequency $(19 \mathrm{~Hz})$ of the pathologic tremor described by Kralic et al. (14) is not simply due to the small size of the mouse, as the authors suggest. Instead, it is likely to be either an artifact of the in-air tail suspension recording technique or a specific characteristic of mice with the $\mathrm{GABA}_{\mathrm{A}}$ receptor $\alpha 1$ subunit deletion. Whether this difference represents a true disparity between neural oscillatory mechanisms or myokinetics in mice and humans must await the discovery and phenotypic description of a similar homozygous loss of function mutation of the human $\mathrm{GABA}_{\mathrm{A}}$ receptor $\alpha 1$ subunit. cally observed in human ET. Since a continu-
Second, while some patients with ET exhibit subtle gait difficulties, the decreased ability of the mutant mice to remain on a rotating rod implies more significant vestibular or cerebellar incoordination. The latter discrepancy may partly reflect the fact that the homozygous knockout mice used in this study entirely lack $\mathrm{GABA}_{\mathrm{A}}$ receptor $\alpha 1$ subunits, whereas patients with a haploinsufficient condition would have the activity of this receptor subunit reduced by only onehalf. In this case, one might still expect to see tremor without ataxia in heterozygous $\mathrm{GABA}_{\mathrm{A}}$ receptor $\alpha 1^{+/-}$mice; however, these were not examined.

One example of indirect evidence that the $\mathrm{GABA}_{\mathrm{A}}$ receptor might be involved in ET is the observation that the anticonvulsant topiramate, which has multiple activities that may contribute to its neurostabilizing effects, including effects at sodium, calci$\mathrm{um}$, and potassium channels, and at $\mathrm{GABA}_{\mathrm{A}}$ receptors, has been found to be effective in some patients with ET (16).

\section{Animal models are windows into human diseases}

In the most general sense, however, the $\mathrm{GABA}_{\mathrm{A}}$ receptor $\alpha 1$ knockout model is indeed essential, since knockout models of other $\mathrm{GABA}_{\mathrm{A}}$ receptor subunits (e.g., $\alpha 5, \alpha 6, \beta 2$, $\beta 3, \gamma 2$,) do not display tremor, nor do models containing gene deletions impairing other steps in GABAergic transmission, including GABA synthesis (17). It is also interesting that deletion of the $\mathrm{GABA}_{\mathrm{A}}$ receptor $\alpha 1$ gene leads to tremor, since point mutations in the same and related subunits of this gene give rise to entirely different human phenotypes that lack tremor but induce epilepsy $(18,19)$.

Assuming that a subset of clinical ET disorders linked to defective GABAergic $\alpha 1$ subunit receptors is ultimately identified in humans, what does this new mouse model tell us about GABA neurotransmission and tremor circuitry? Can it help us localize the site and determine the onset of the excitability defect? Not easily. Since the $\mathrm{GABA}_{\mathrm{A}}$ receptor $\alpha 1$ subunit is normally switched on at birth and combines with other $\alpha, \beta$, and $\gamma$ subunits to form the pentameric ligand-gated chloride ion channel mediating GABAergic inhibition throughout the neuraxis, considerable analysis will be required to explain the highly selective mechanism for delayed-onset tremor.

The most prevalent $\mathrm{GABA}_{\mathrm{A}}$ receptor population in the brain is the pentamer containing subunits $\alpha 1, \alpha 1, \beta, \beta$, and $\gamma(20)$. In the absence of the $\alpha 1$ subunit, alternative members of the $\alpha$ subunit family are substituted 
in the cells where these receptors are normally expressed (Figure 1). This means that all remaining GABAergic transmission in the $\mathrm{GABA}_{A}$ receptor $\alpha 1$-deficient mouse relies upon a mixture of $\mathrm{GABA}_{A}$ receptors that in many cells are composed of novel $\alpha 2-3 / \beta$, $\beta / \gamma$ subunit combinations. Since these alternative receptors vary in kinetic behavior and pharmacology according to cell type and region, characterizing inhibitory transmission in the mutant nervous system will be a lengthy process, and the design of an effective drug to target this altered pattern may be dependent upon both age and region (21). The authors postulate that the tremor in $\mathrm{GABA}_{\mathrm{A}}$ receptor $\alpha 1^{-/-}$mice may result from a loss of $\mathrm{GABA}_{\mathrm{A}}$ signaling by cerebellar purkinje cells but without actual degeneration of the cells (14). This would be consistent with the pathological studies in ET, which have so far not demonstrated microscopic cerebellar pathology in postmortem brains of patients with ET (22). It should be noted, however, that the $\mathrm{GABA}_{\mathrm{A}}$ receptor $\alpha 1$ mutant mice have an overall reduction in brain size of about $15 \%$, limiting the ability to directly attribute the tremor to this specific purkinje cell-signaling defect.

\section{Conclusions}

In summary, this new model of inherited tremor is welcome because it places $\mathrm{GABA}_{\mathrm{A}}$ receptor $\alpha 1$, a well-known ligand-gated channel subunit, on the list of possible candidate genes for evaluation as a pathogenic cause of human ET and provides an excellent model for tracing the developmental cascade of signaling changes that lead to a tremulous phenotype. If the lessons learned from the investigation of other neurological disorders in mice are any guide, a human variant will soon be in hand; however, whether the human mutant will display tremor is not yet known. Only at that point can we comfortably conclude that the mouse mutant provides a truly "essential" model of the disorder.

Address correspondence to: Joseph Jankovic, Parkinson's Disease Center and Movement Disorders Clinic and Department of Neurology, Baylor College of Medicine, 6550 Fannin, Suite 1801, Houston, Texas 77030, USA. Phone: (713) 798-5998; Fax: (713) 798-6808; E-mail: josephj@bcm.tmc.edu.

1. Dogu, O., et al. 2003. Prevalence of essential tremor: Door-to-door neurologic exams in Mersin Province, Turkey. Neurology. 61:1804-1806.

2. Moghal, S., Rajput, A.H., D’Arcy, C., and Rajput, R. 1994. Prevalence of movement disorders in elderly community residents. Neuroepidemiology. 13:175-178

3. Gulcher, J.R., et al. 1997. Mapping of a familial essential tremor gene, FET1, to chromosome $3 \mathrm{q} 13$. Nat Genet. 17:84-87.

4. Higgins, J., et al. 2004. Haplotype analysis at the ETM2 locus in a Singaporean sample with familial essential tremor. Clin. Genet. 66:353-357.

5. Higgins, J.J., et al. 2005. A variant in the HS1-BP3 gene is associated with familial essential tremor. Neurology. 64:417-421.

6. Jankovic, J. 2002. Essential tremor: a heterogenous disorder. Mov. Disord. 17:638-644

7. Ondo, W.G., et al. 2003. Hearing impairment in essential tremor. Neurology. 61:1093-1097.

8. Deng, H., Le, W., and Jankovic, J. 2005. Parkinson's disease, essential tremor, and premutation alleles of the FMR1 gene. JAMA. In press.

9. Pagan, F.L., Butman, J.A., Dambrosia, J.M., and Hallett, M. 2003. Evaluation of essential tremor with multi-voxel magnetic resonance spectroscopy. Neurology. 60:1344-1347.

10. Ushe, M., et al. 2004. Effect of stimulation frequency on tremor suppression in essential tremor. Mov. Disord. 19:1163-1168.

11. McAuley, J.H. 2001. Does essential tremor originate in the cerebral cortex? Lancet. 357:492-494.

12. Hellwig, B., et al. 2001. Tremor-dominant cortical activity in essential tremor. Lancet. 357:519-523.

13. Wilms, H., Sievers, J., and Deuschl, G. 1999. Animal models of tremor. Mov. Disord. 14:557-571.

14. Kralic, J.E., et al. 2005. Genetic essential tremor in $\gamma$-aminobutyric acid receptor $\alpha 1$ subunit knockout mice. J. Clin. Invest. 115:774-779. doi:10.1172/ JCI200523625.

15. Jankovic, J., Madisetty, J., and Vuong, K.D. 2004. Essential tremor among children. Pediatrics. 114:1203-1205

16. Jankovic, J., et al. 2004. A multicenter, double-blind, placebo-controlled trial of topiramate in essential tremor. Mov. Disord. 19(Suppl. 9):S448-S449.

17. Kash, S.F., et al. 1997. Epilepsy in mice deficient in the $65-\mathrm{kDa}$ isoform of glutamic acid decarboxylase. Proc. Natl. Acad. Sci. U. S. A. 94:14060-14065.

18. Baulac, S., et al. 2001. First genetic evidence of GABA(A) receptor dysfunction in epilepsy: a mutation in the gamma2-subunit gene. Nat. Genet. 28:46-48.

19. Cossette, P., Lortie, A., Vanasse, M., Saint-Hilaire, J.M., and Rouleau, G.A. 2005. Autosomal dominant juvenile myoclonic epilepsy and GABRA1. Adv. Neurol. 95:255-263.

20. Benke, D., et al. 2004. Analysis of the presence and abundance of GABAA receptors containing two different types of alpha subunits in murine brain using point-mutated alpha subunits. J. Biol. Chem. 279:43654-43660.

21. Mohler, H., Fritschy, J.M., Crestani, F., Hensch, T., and Rudolph, U. 2004. Specific GABA(A) circuits in brain development and therapy. Biochem. Pharmacol. 68: $1685-1690$.

22. Rajput, A., Robinson, C.A., and Rajput, A.H. 2004. Essential tremor course and disability: A clinicopathologic study of 20 cases. Neurology. 62:932-936.

\title{
Illuminating the role of type I IFNs in colitis
}

\section{Stefan Wirtz and Markus F. Neurath}

Laboratory of Immunology, I. Medical Clinic, University of Mainz, Mainz, Germany.

\begin{abstract}
Recently, type I interferons IFN- $\alpha$ and IFN- $\beta($ IFN- $\alpha / \beta)$ have been evaluated in pilot clinical trials for the treatment of active ulcerative colitis. However, the underlying mechanisms that may contribute to a potential therapeutic effect are incompletely understood. A new study in this issue demonstrates a protective role for IFN- $\alpha / \beta$, induced by activation of a Toll-like receptor 9-dependent pathway, in a rodent model of experimental colitis (see the related article beginning on page 695).
\end{abstract}

Nonstandard abbreviations used: CPG ODN, CpGcontaining oligodeoxynucleotide; DSS, dextran sulphate sodium; IBD, inflammatory bowel disease; TLR9, Toll-like receptor 9; UC, ulcerative colitis.

Conflict of interest: The authors have declared that no conflict of interest exists.

Citation for this article: J. Clin. Invest. 115:586-588 (2005). doi:10.1172/JCI200524518.
The pathogenesis of Crohn disease and of ulcerative colitis (UC), the 2 major forms of inflammatory bowel disease (IBD), involve a complex interplay among certain genetic, environmental, and immunological factors. Research in the last decade resulted in considerable progress in defining key inflammatory pathways in the inflamed gut and identifying new potential therapeutic targets. In particular, administration or manipulation of immunomodulatory cytokines have been proposed as alternative therapeutic strategies to modulate or inhibit proinflammatory cytokine production in IBD. Although, in the case of Crohn disease, novel strategies to inhibit TNF- $\alpha$ (e.g., administration of the anti-TNF- $\alpha$ monoclonal antibody, infliximab), IFN- $\gamma$, and IL-12 have been used in clinical trials $(1,2)$, relatively few successful studies using anticytokine agents for the treatment of UC have been performed. Recently, type I IFN- $\alpha$ 